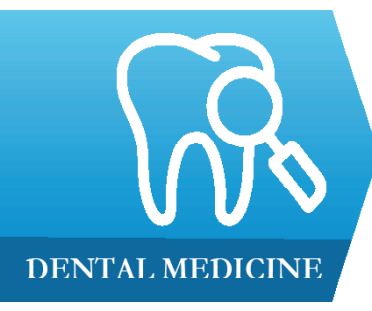

1) Department of Oral Medicine and Maxillofacial Radiology, Faculty of Dental Medicine, Lebanese University, Beirut, Lebanon

2) Department of Emergency Medicine, American University of Beirut, Beirut, Lebanon

DOI: $10.15386 / \mathrm{mpr}-1666$

Manuscript received: 21.04 .2020

Received in revised form: 15.05.2020

Accepted: 30.05.2020

Address for correspondence:

aoungeorges@yahoo.com

This work is licensed under a Creative Commons Attribution-NonCommercialNoDerivatives 4.0 International License

\section{Styloid process elongation in a sample of Lebanese population: a consideration for the prevention of Eagle syndrome}

Georges Aoun ${ }^{1}$, Nour Srour ${ }^{1}$, Abbass El-Outa ${ }^{2}$, Ibrahim Nasseh ${ }^{1}$

\begin{abstract}
Background. The objective of this study was to investigate the prevalence and patterns of styloid process elongation in a general Lebanese population sample.

Methods. Digital panoramic radiographs of 489 Lebanese adults $(218$ males and 271 females, mean age of $47.56 \pm 16.149$ ) were included in this retrospective study. First, we screened for detection of elongated styloid process, then we analyzed these cases and classified the elongation types. Data obtained were transformed into SPSS v24 and descriptive and inferential analyses were done.
\end{abstract}

Results. In our sample, elongated styloid process was seen in 76 cases $(15.5 \%)$ (45/271 women and 31/218 men). Despite no significant gender predisposition, females were slightly more affected than males (59.2\% females to $40.8 \%$ males). As for the age, elongation was significantly more likely to be present at 45-64 years of age. The right side was slightly more affected than the left side $(86.8 \%$ vs. $76.3 \%$ respectively), with type 1 elongation as the most common. Nevertheless, bilateral elongation was much more common than unilateral elongation $(63.2 \%)$.

Interestingly, females were more likely to suffer from bilateral elongation $(64.58 \%)$ compared to men $(35.41 \%)$.

Conclusion. Elongated styloid process represents a common finding detected fortuitously on panoramic radiographs. Therefore, being a main feature in Eagle syndrome, dentists should be aware of this clinical entity and actively screen for it.

Keywords: elongated styloid process syndrome, Lebanon, Eagle syndrome, panoramic radiography

\section{Introduction}

The styloid process (SP) is a thin cylindrical bony structure that projects downward and forward from the inferior surface of the petrous temporal bone anteromedially to the stylomastoid foramen. It is located between the carotid arteries and presents the site of insertion of the stylohyoid, styloglossus, and stylopharyngeus muscles, as well as to the stylohyoid and stylomandibular ligaments [1,2].

Many authors have reported that the normal length of the SP ranges from 20 to $30 \mathrm{~mm}$; consequently, longer $\mathrm{SP}$ is considered elongated $[3,4]$. For others, the SP is within normal size as long as it does not extend below the mandibular foramen and otherwise elongated $[5,6]$. Indeed, elongated SP has been investigated in different populations by different techniques. In fact, a very wide variation of the prevalence of SP elongation was reported, ranging from 4 to $30 \%$ [7-9].

A variety of theories have been proposed to clarify the SP elongation since initially described by the American otorhinolaryngologist Watt. W. Eagle, in 1937 [10]. Several researchers described a congenital etiology of such finding; others, however, postulated that calcification/ossification of the stylohyoid ligament of unclear cause 
may lead to such elongation; besides, it has been reported that development of bony tissue at the site of insertion of the stylohyoid ligament may contribute to this condition as well $[11,12]$.

Usually, elongated SPs are asymptomatic, with only 4 to $10.3 \%$ present with clinical symptoms [10] defining Eagle syndrome, also known as styloid or stylohyoid syndrome; when symptomatic, elongated SP is reported to possess weak to no correlation with pain intensity and clinical complications [13]. Nevertheless, studies suggested no association of calcification/ossification degree with clinical signs [11].

In fact, Eagle syndrome usually presents with nonspecific symptoms, typically including dysphagia and cervicofacial pain most likely due to the compression of surrounding nerves [2]. Additionally, uncommon symptoms may include neuralgia (mainly of trigeminal or glossopharyngeal nerve) $[9,14,15]$, tinnitus, otalgia, orbital and maxillary radiating pain $[2,15]$. Furthermore, elongated SP can contribute to the development of transient ischemic attacks or ischemic stroke by compressing the carotid arterial system, and in rare cases, carotid dissection [16]; this takes place in the stylo-carotid syndrome that is caused by pressure of the elongated SP on the internal/external carotid artery and the sympathetic fibers encircled within these vessels. This condition is usually characterized by pain and recurrent syncope provoked by cervical movements, especially rotational [17]. Similarly, compression of dural spaces and of the internal jugular vein in so-called "Eagle-jugular syndrome" can ultimately lead to altered cerebral perfusion, with increased intracranial pressure and risk of cerebral hemorrhage $[18,19]$. This places additional clinical implication for the dental professional: special care must be taken during dental treatment to avoid positioning the patient in postures that cause further compression of any of these vital structures and decrease risk of aforementioned complications, such as head rotation and wide mouth opening [20,21].

In such severe cases, surgical shortening of the SP may be performed, either via intraoral or extra-oral approaches leading to marked improvement. Alternative nonsurgical treatments have been proposed but none have been were shown to be successful [17].

Eagle's syndrome is often misdiagnosed and accidentally detected during radiological exams [2]. When evaluating signs of Eagle syndrome, the differential diagnosis must include other more common conditions first: tonsillitis, dysphagia and/or odynophagia of other cause, odontogenic pain, arthritis, and tongue and oropharyngeal tumors trigeminal and/or glossopharyngeal neuralgia not induced by Eagle syndrome, sphenopalatine ganglia neuralgia, primary headaches (migraine, cluster), temporomandibular disorders, myofascial pain affecting neck and masticatory muscles, and upper aerodigestive tract tumors [22-24]. Upon suspicion of Eagle syndrome, reproducing pain perceived by the patient is of important clinical relevance. In fact, it may be very useful to palpate the SP with the index finder placed over the tonsillar fossa intra-orally with gentle pressure application; if such palpation triggers the painful complaint, this is in support of a clinical diagnosis of Eagle syndrome [9,22,25].

Given the fact that the diagnosis of Eagle syndrome is difficult, different imaging modalities are useful in detecting SP elongation. Such techniques include panoramic radiograph, lateral skull view radiograph, and non-angled (PA view) and angled (Towne's view) posteroanterior skull radiographs. Furthermore, three-dimensional imaging techniques such as computed tomography (CT) scan and conebeam computed tomography (CBCT) allow for complete detailed visualization (length, angulation and relation to contiguous structures) $[26,27]$. However, since panoramic radiography is a frequently-used imaging modality in dental offices, dental professionals are able to incidentally detect elongated when examining patients' panoramic radiographs.

In the absence of any radiologic investigation specifically targeted for elongated SP in Lebanon, the aim of this study was to assess its prevalence in a sample of Lebanese population by means of digital panoramic radiographs.

\section{Methods}

This retrospective study was conducted on 489 archived digital panoramic radiographs of Lebanese adults (218 males and 271 females) taken initially for oral and dental diagnostic purposes in the Oral Medicine and Dentomaxillofacial Radiology Department of the Faculty of Dental Medicine at the Lebanese University, Beirut, Lebanon. The mean age of the population was $47.56 \pm$ 16.149 years.

According to the faculty regulations, all patients always provide their informed consent during their initial presentation for anonymous future use of their radiographs for research aims; panoramic radiographs of patients who refuse to consent are not included in the archive.

All images were acquired by the Carestream ${ }^{\circledR}$ digital panoramic unit, with settings set between $60-90$ $\mathrm{kV}$ and 6-10 $\mathrm{mA}$; exposure time was $20 \mathrm{~s}$.

Exclusion criteria comprised radiographs with absence of information about patients' age and gender, bad quality and/or not showing the SP.

Data was evaluated by a maxillofacial radiologist having more than 20 years of experience; images were assessed on the same monitor over eight sessions spaced by a 10 -days period. To reduce the errors, 75 images were randomly chosen and rechecked 15 days later. 
Table I. Type of elongated SP according to combined Langlais and modified MacDonald-Jankowski classifications.

\begin{tabular}{l|l} 
Type & Characteristics \\
Type 0 (Normal) & $\begin{array}{l}\text { Non elongated SP; the tip of the process does not cross the mid portion of mandible body } \\
\text { Type } 1 \text { (Elongated) }\end{array}$ \\
$\begin{array}{l}\text { Uninterrupted SP; the tip of the process cross the mid portion of mandibular body. } \\
\text { The SP is apparently joined to the mineralized stylomandibular or stylohyoid ligament by a single } \\
\text { pseudoarticulation, which is usually located superior to a level tangential to the inferior border of the } \\
\text { mandible. }\end{array}$ \\
$\begin{array}{l}\text { Two or more segments are seen, with interruptions either above or below the level of the inferior border } \\
\text { of the mandible. }\end{array}$
\end{tabular}
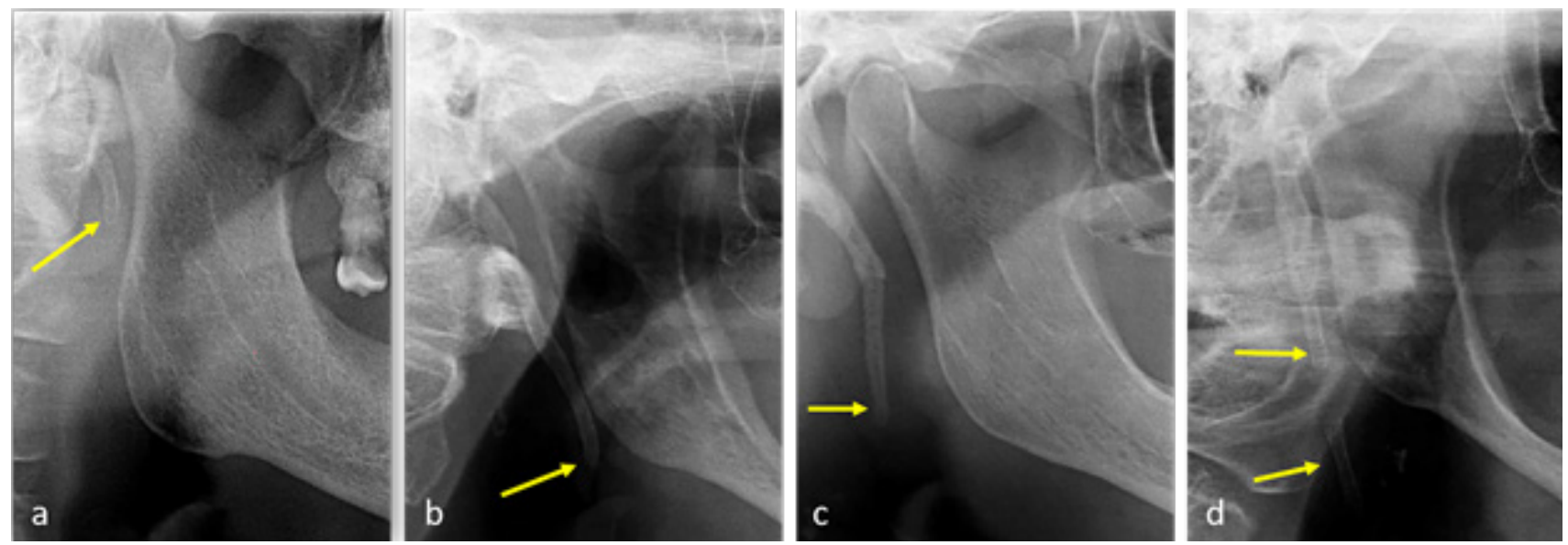

Figure 1. Radiographs showing different types of SP; a: Type 0; b: Type 1; c: Type 2; d: Type 3.

Styloid processes morphology was assessed as per Langlais' classification [28] and SP was considered elongated when it extended below the mandibular foramen, as defined by MacDonald-Jankowski [6] (Table I) (Figure 1).

The relationships between elongated SP, gender, age and location (right/left) were assessed. Data entry and statistical analyses were conducted using IBM SPSS for Windows, version 24 (IBM Corp., Armonk, N.Y., USA). Descriptive statistics were performed, and Shapiro-Wilk was used for normality assessment. Moreover, KruskalWallis test, Mann-Whitney test, post-hoc tests, chi-square and Fisher's exact tests, and regression models were done to evaluate associations and compare results. Level of significance was set at $\mathrm{p}=0.05$.

\section{Results}

The 489 digital panoramic radiographs assessed were divided into 218 and 271 males and females respectively. Population age ranged between 18 and 86 years with a mean of $47.56 \pm 16.149$ years.

In this population, prevalence of elongated SP was 76 cases $(15.5 \%)$. Among these positive cases, mean age was around 51 years \pm 16.2. Female patients were more commonly affected than males with 45 (59.2\%) and 31 (40.8\%) cases respectively (ratio male to female of $1: 1.45$ ) (Table II), although this difference was not statistically significant $(\mathrm{p}=0.138)$.

Moreover, there were no significant association between gender and SP elongation $(\mathrm{p}=0.531)$.

Among patients with elongated SP, females were more likely to suffer from bilateral elongation (31 out of $48 ; 64.58 \%$ ) compared with men (17 out of $48 ; 35.41 \%$ ). However, this difference was not statistically significant $(\mathrm{p}=0.235)$.

In both males and females, SP elongation type 1 was more prevalent than other patterns on both right and left sides. Furthermore, bilateral SP elongation (63.2\%) was more common than unilateral elongation $(36.8 \%)$. Additionally, the right side was slightly more affected than left side.

As for the age, Mann-Whitney test showed a significant association with SP elongation $(\mathrm{p}=0.030)$ with the age range 45-64 years significantly more affected (Chi-square test, $\mathrm{p}=0.000$ ). On the contrary, there was no association between age and elongation pattern (unilateral/ bilateral) $(\mathrm{p}=0.321)$. 
Table II. Summarized descriptive statistics of cases of styloid process elongation.

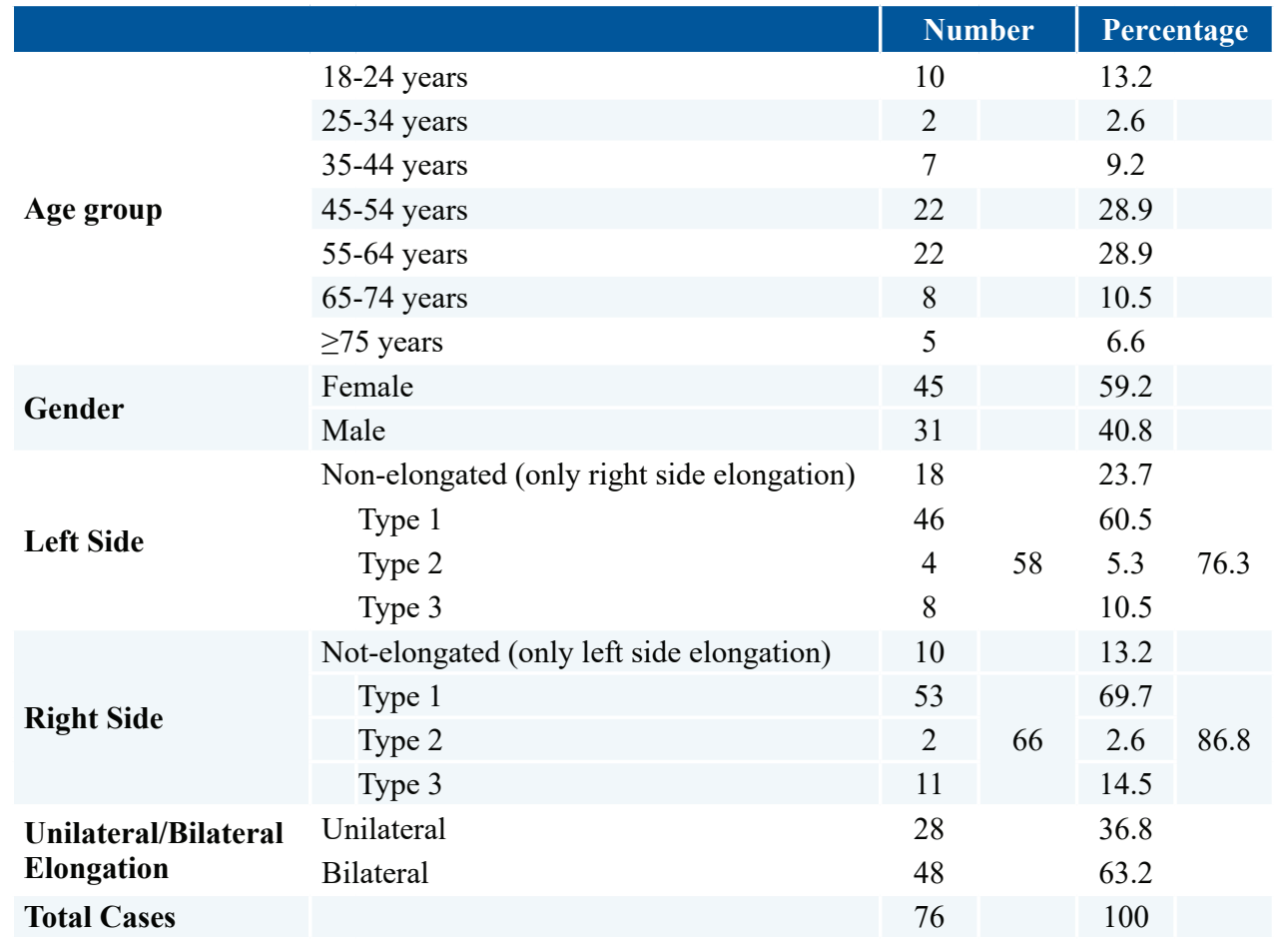

\section{Discussion}

The styloid complex includes the SP of the temporal bone, the stylohyoid ligament and the lesser horn of the hyoid bone; embryologically, it derives from the Reichert's cartilage described as a continuous cartilaginous structure in the second pharyngeal arch $[29,30]$.

Reichert's cartilage's ossification forms the SP and the segment of this cartilage extending from the SP to the lesser horn of the hyoid bone gives the stylohyoid ligament $[30,31]$.

Custodio et al.[1], Vadgaonkar et al. [2], Natsis et al. [32] , Sakaew et al. [33] evaluated SP elongation on dry skulls in Brazilian, Indian, Greek and Thai populations, respectively; other studies, such as that conducted by Kursoglu et al. [4] on Turkish, More and Asrani [26] on Indian, Shaik et al. [31] on Saudian and Al-Khateeb et al. [34] on Jordanian populations were performed based on panoramic radiographs.

Furthermore, some studies used more advanced imaging technologies: Gözil et al. [35], Basekim et al. [36] and Cullu et al. [37] used CT to evaluate SP elongation in different samples of the Turkish population, while Andrei et al. [38] and Öztunç et al. [39] used CBCT in Romanian and Turkish samples, respectively.

In all these studies, two techniques were proposed to confirm elongated SP:

- SP measuring more than $30 \mathrm{~mm}$ in length $[1,3,10,29,31,33]$
- Tip of SP extended beneath the mandibular foramen $[5,6]$; this was the technique we adopted in our study.

In line with several authors, we avoided analyzing lengths of prolonged SPs due to the huge variations attributed to technical (panoramic radiography machine differences and magnifications they provide, digital vs. manual measurement, and arbitrary calibration) and epidemiological (ethnic, genetic and racial variations) reasons $[5,40,41]$. Therefore, we have sufficed to screen for elongated vs. non-elongated processes (as determined by MacDonald-Jankowski) [6], and we have compared the types of such elongations according to Langlais classification [28].

In our sample of Lebanese adults, $15.5 \%$ of the cases presented elongated SP. Compared to the studies utilizing the same classification, our prevalence supports what was reported by Omami (17.2\% in a Libyan sample) [5], but is higher than that of MacDonald-Jankowski's (8.6\% in a sample of Hong Kong Chinese and $7.8 \%$ in an English sample) [6].

As for SP morphology, our results showed that the type 1 was the most retrieved; this finding corroborates the ones of More and Asrani [26] in Indian samples, Shaik et al. [31] in a Saudi sample, and Chabikuli and Noffke [41] in a South African sample.

In our investigation, women were slightly more affected, although no significant difference could be 
proven; this is similarly reported by Omami [5], Chabikuli and Noffke [41] and Vieira et al. [42].

Our study also showed 28 out of 76 cases unilateral elongated SP against 48 bilateral; this is consistent with the ones of More and Asrani [26] and Vieira et al. [42], as bilateral elongations constituted the majority.

Finally, despite being the first study to evaluate the SP elongation in a Lebanese population, limitations of our study include the limited measurement of the SP. Therefore, in future studies, precise digital measurement software with three dimensional imaging modalities may be used to provide accurate details. Additionally, a larger sample size may be warranted to confirm our findings. Thus, exact conclusions must be delayed until future researches validate our results.

\section{Conclusions}

To the best of our knowledge, this is the first study in terms of investigation of the SP elongation in Lebanon. This SP natural variation could be fortuitously noticed on digital panoramic radiographs taken for diagnostic purposes in everyday dental practice. Dentists should be aware about this condition in order to avoid misinterpretation of symptoms related to Eagle syndrome.

\section{References}

1. Custodio AL, Silva MR, Abreu MH, Araújo LR, de Oliveira LJ. Styloid process of the temporal bone: Morphometric analysis and clinical implications. Biomed Res Int. 2016;2016: 8792725.

2. Vadgaonkar R, Murlimanju BV, Prabhu LV, Rai R, Pai MM, Tonse M, et al. Morphological study of styloid process of the temporal bone and its clinical implications. Anat Cell Biol. 2015;48:195-200.

3. Ilgüy M, Ilgüy D, Güler N, Bayirli G. Incidence of the type and calcification patterns in patients with elongated styloid process. J Int Med Res. 2005;33:96-102.

4. Kursoglu P, Unalan F, Erdem T. Radiological Evaluation of the Styloid Process in Young Adults Resident in Turkey's Yeditepe University Faculty of Dentistry. Oral Surg Oral Med Oral Pathol Oral Radiol Endod. 2005;100:491-494.

5. Omami G. Calcification of the stylohyoid complex in Libyans. Saudi Dent J. 2018;30:151-154.

6. MacDonald-Jankowski DS. Calcification of the stylohyoid complex in Londoners and Hong Kong Chinese. Dentomaxillofac Radiol. 2001;30:35-39.

7. Sridevi K, Mahesh N, Krishnaveni B, Deepika ADN, Thejasri V, Leninson BHD. Evaluation of styloid process and its anatomical variations: A digital panoramic study with systematic review. J Int Soc Prev Community Dent. 2019;9:256-262.

8. Keur JJ, Campbell JP, McCarthy JF, Ralph WJ. The clinical significance of the elongated styloid process. Oral Surg Oral Med Oral Pathol. 1986;61:399-404.
9. Badhey A, Jategaonkar A, Anglin Kovacs AJ, Kadakia S, De Deyn PP, Ducic Y, et al. Eagle syndrome: A comprehensive review. Clin Neurol Neurosurg. 2017;159:34-38.

10. Eagle WW. Elongated styloid process: Report of two cases. Arch Otolaryngol. 1937;25:584-587.

11. Camarda AJ, Deschamps C, Forest D. I. Stylohyoid chain ossification: A discussion of etiology. Oral Surg Oral Med Oral Pathol. 1989;67:508-514.

12. Balbuena L Jr, Hayes D, Ramirez SG, Johnson R. Eagle's syndrome (elongated styloid process). South Med J. 1997;90:331-334.

13. Savranlar A, Uzun L, Uğur MB, Özer T. Three-dimensional CT of Eagle's syndrome. Diagn Interv Radiol. 2005;11:206209.

14. Siqueira JT, Lin HC, Nasri C, Siqueira SR, Teixeira MJ, Heir $\mathrm{G}$, et al. Clinical study of patients with persistent orofacial pain. Arq Neuropsiquiatr. 2004;62:988-996.

15. Soh KB. The glossopharyngeal nerve, glossopharyngeal neuralgia and the Eagle's syndrome--current concepts and management. Singapore Med J. 1999; 40:659-665.

16. Aydin E, Quliyev H, Cinar C, Bozkaya H, Oran I. Eagle syndrome presenting with neurological symptoms. Turk Neurosurg. 2018;28:219-225.

17. Sadaksharam J, Singh K. Stylocarotid syndrome: An unusual case report. Contemp Clin Dent. 2012;3:503-506.

18. Costantinides F, Vidoni G, Bodin C, Di Lenarda R. Eagle's syndrome: signs and symptoms. Cranio. 2013;31:56-60.

19. Zamboni P, Scerrati A, Menegatti E, Galeotti R, Lapparelli $\mathrm{M}$, Traina $\mathrm{L}$, et al. The eagle jugular syndrome. BMC Neurol. 2019;19:333.

20. Ranjan V, Rai S, Misra D, Panjwani S. Eagle's syndrome veiling as pain of odontogenic origin: Report of two cases with cone beam computed tomography illustration. Natl J Maxillofac Surg. 2015;6:219-223.

21. Li S, Blatt N, Jacob J, Gupta N, Kumar Y, Smith S. Provoked Eagle syndrome after dental procedure: A review of the literature. Neuroradiol J. 2018;31:426-429.

22. Thoenissen P, Bittermann G, Schmelzeisen R, Oshima T, Fretwurst T. Eagle's syndrome-A non-perceived differential diagnosis of temporomandibular disorder. Int J Surg Case Rep. 2015;15:123-126.

23. Pinheiro TG, Soares VY, Ferreira DB, Raymundo IT, Nascimento LA, De Oliveira CA. Eagle's syndrome. Int Arch Otorhinolaryngol. 2013;17:347-350.

24. Khandelwal S, Hada YS, Harsh A. Eagle's syndrome A case report and review of the literature. Saudi Dent J. 2011;23:211-215.

25. Piagkou MN, Anagnostopoulou S, Kouladouros K, Piagkos G. Eagle's syndrome: A review of the literature. Clin Anat. 2009;22:545-558.

26. More CB, Asrani MK. Evaluation of the styloid process on digital panoramic radiographs. Indian J Radiol Imaging. 2010;20:261-265.

27. Scavone G, Caltabiano DC, Raciti MV, Calcagno MC, Pennisi M, Musumeci AG, et al. Eagle's syndrome: a case report and CT pictorial review. Radiol Case Rep. 2018;14:141-145. 
28. Langlais RP, Miles DA, Van Dis ML. Elongated and mineralized stylohyoid ligament complex: A proposed classification and report of a case of Eagle's syndrome. Oral Surg Oral Med Oral Pathol. 1986;61:527-532.

29. Patil S, Ghosh S, Vasudeva N. Morphometric study of the styloid process of temporal bone. J Clin Diagn Res. 2014;8:AC04-AC06.

30. Rodríguez-Vázquez JF, Mérida-Velasco JR, Verdugo-López S, Sánchez-Montesinos I, Mérida-Velasco JA. Morphogenesis of the second pharyngeal arch cartilage (Reichert's cartilage) in human embryos. J Anat. 2006;208:179-189.

31. Shaik MA, Naheeda, Kaleem SM, Wahab A, Hameed S. Prevalence of elongated styloid process in Saudi population of Aseer region. Eur J Dent. 2013;7:449-454.

32. Natsis K, Repousi E, Noussios G, Papathanasiou E, Apostolidis S, Piagkou M. The styloid process in a Greek population: an anatomical study with clinical implications. Anat Sci Int. 2015;90:67-74.

33. Sakaew W, Arnanteerakul T, Somintara S, Ratanasuwon S, Uabundit N, Iamsaard S, et al. Sexual Dimorphism Using the Interstyloid Distances and Clinical Implication for Elongated Styloid Process in Northeastern Thailand. Int J Morphol. 2016;34:1223-1227.

34. Al-Khateeb TH, al Dajani TM, Al Jamal GA. Mineralization of the stylohyoid ligament complex in a Jordanian sample: A clinicoradiographic study. J Oral Maxillofac Surg. 2010;68:1242-1251.

35. Gözil R, Yener N, Çalgüner E, Araç M, Tunç E, Bahcelioğlu
M. Morphological characteristics of styloid process evaluated by computerized axial tomography. Ann Anat. 2001;183:527-535.

36. Başekim CÇ, Mutlu H, Güngör A, Şilit E, Pekkafali Z, Kutlay $\mathrm{M}$, et al. Evaluation of styloid process by three-dimensional computed tomography. Eur Radiol. 2005;15:134-139.

37. Cullu N, Deveer M, Sahan M, Tetiker H, Yilmaz M. Radiological evaluation of the styloid process length in the normal population. Folia Morphol (Warsz). 2013;72:318321.

38. Andrei F, Motoc AG, Didilescu AC, Rusu MC. A 3D cone beam computed tomography study of the styloid process of the temporal bone. Folia Morphol (Warsz). 2013;72:29-35.

39. Öztunç H, Evlice B, Tatli U, Evlice A. Cone-beam computed tomographic evaluation of styloid process: a retrospective study of 208 patients with orofacial pain. Head Face Med. 2014; $10: 5$

40. Sudhakara Reddy R, Sai Kiran C, Sai Madhavi N, Raghavendra MN, Satish A. Prevalence of elongation and calcification patterns of elongated styloid process in south India. J Clin Exp Dent. 2013;5:e30-e35.

41. Chabikuli NJ, Noffke CCE. Styloid process elongation according to age and gender: a radiological study. S Afr Dent J. 2016;71:470-473.

42. Vieira EM, Guedes OA, Morais SD, Musis CR, Albuquerque PA, Borges ÁH. Prevalence of elongated styloid process in a central Brazilian population. J Clin Diagn Res. 2015;9:ZC90ZC92. 